\title{
Erratum to: Tafamidis in transthyretin amyloidosis: a guide to its use in delaying peripheral neurological impairment in patients with stage 1 polyneuropathy
}

\author{
Kate McKeage $^{1} \cdot$ Katherine A. Lyseng-Williamson $^{1} \cdot$ Lesley J. Scott $^{1}$
}

Published online: 1 February 2017

(C) Springer International Publishing Switzerland 2017

\section{Erratum to: Drugs Ther Perspect \\ DOI 10.1007/s40267-016-0368-4}

In the online version of the original article, Fig. 2 is incorrect.

The correct version is given below.

The online version of the original article (as corrected) can be found under doi:10.1007/s40267-016-0368-4.

Katherine A. Lyseng-Williamson dtp@adis.com

1 Springer, Private Bag 65901, Mairangi Bay, Auckland 0754, New Zealand 
Patient care guidelines

Patient assessed as having TTR-FAP at symptomatic stage 1 (i.e. able to walk unaided outside)

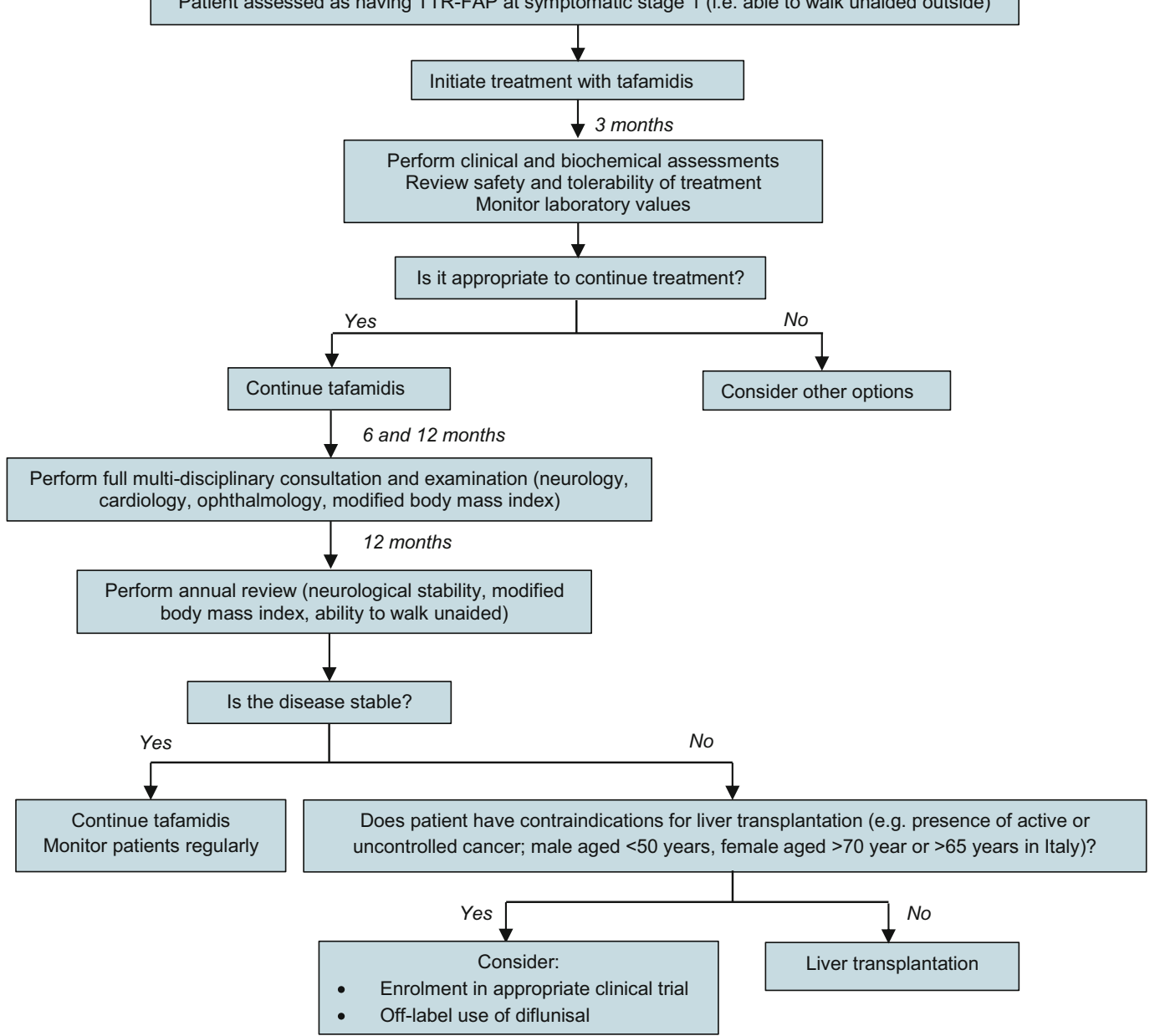

Fig. 2 Patient care guidelines for the treatment of stage 1 transthyretin familial amyloid polyneuropathy (TTR-FAP), as suggested by Adams et al. [4] 